\title{
Chronic pain and adult hippocampal neurogenesis: translational implications from preclinical studies
}

\author{
This article was published in the following Dove Press journal: \\ Journal of Pain Research \\ 21 September 2017 \\ Number of times this article has been viewed
}

\author{
Mariagrazia Grilli \\ Laboratory of Neuroplasticity, \\ Department of Pharmaceutical \\ Sciences, University of Piemonte \\ Orientale, Novara, Italy
}

Correspondence: Mariagrazia Grilli Department of Pharmaceutical Sciences, University of Piemonte Orientale, Via Bovio 6, 28100 Novara, Italy

Tel +390321375828

Fax +390321375821

Email mariagrazia.grilli@uniupo.it

\begin{abstract}
Adult hippocampal neurogenesis (ahNG) occurs in the human brain. Adult generated neurons have been proposed to functionally contribute to relevant hippocampal functions such as learning and memory, mood regulation, and stress response. Learning, environmental enrichment, and physical exercise exert positive effects on ahNG. In parallel, these proneurogenic stimuli have been shown to ameliorate cognitive performance and/or depressive-like behavior in animal models. Conversely, aging, social isolation, and chronic stress exert negative effects on ahNG. Interestingly, reduction of hippocampal neurogenesis is suggested to potentially contribute to cognitive decline and mood alterations associated with aging and several neuropsychiatric disorders. Clinical observation demonstrates that patients affected by chronic pain often exhibit increased anxiety and depression, impaired cognitive flexibility, and memory capacities. As of today, our understanding of the molecular and cellular events that may underlie the comorbidity of chronic pain, depression, and cognitive impairment is limited. Herein we review recent preclinical data suggesting that chronic pain may induce profound changes in hippocampal plasticity, including reduced ahNG. We discuss the possibility that deregulated hippocampal neurogenesis in chronic pain may, at least in part, contribute to cognitive and mood alterations. Based on this hypothesis, the mechanisms underlying chronic pain-associated changes in hippocampal neurogenesis and related functions need to be addressed experimentally. One interesting feature of ahNG is its susceptibility to pharmacological modulation. Again, based on preclinical data we discuss the possibility that, at least in principle, distinct analgesic drugs commonly used in chronic pain states (typical and atypical opiates, $\alpha 2 \delta$ ligands, and acetyl-L-carnitine) may differentially impact ahNG and that this aspect could be taken into account to reduce and/or prevent the potential risk of cognitive and emotional side effects in the clinical setting.
\end{abstract}

Keywords: chronic pain, adult neurogenesis, depression, cognition, opiates, tapentadol, pregabalin

\section{Function, dysfunction, and modulation of adult hippocampal neurogenesis}

Throughout life, new neurons are generated in the dentate gyrus (DG) of the adult mammalian brain, a process referred to as adult hippocampal neurogenesis (ahNG). In that hippocampal region, the SubGranular Zone (SGZ) acts indeed as neurogenic niche, a permissive and instructive microenvironment where adult neural stem/progenitor cells (aNSC/NPC) survive, self-renew, and give rise to intermediate progenitor cells which, in turn, can generate neuroblasts capable of terminal neuronal differentiation. The surviving adult-born cells will eventually become granule neurons and will be functionally integrated into the DG preexisting circuit. ${ }^{1-4}$ 
During the last two decades, extensive research efforts contributed to the concept that adult-born neurons may play a crucial role in several hippocampal-related functions, including selected cognitive functions, pattern discrimination, mood regulation, and stress response. ${ }^{5-10}$ It is also of great interest that ahNG appears deregulated in several neurodegenerative and neuropsychiatric disorders, including major depressive disorder (MDD). ${ }^{11-13}$

ahNG is a remarkably modulable process. In animal models, learning, environmental enrichment (EE), and physical exercise have been shown to produce positive effects on proliferation and differentiation of aNSC/NPC as well as survival of their progeny. In parallel, these proneurogenic stimuli ameliorate cognitive performance or anhedonia in animal models of cognitive impairment or stress-induced depressivelike behavior. ${ }^{14,15}$ On the contrary, aging and chronic stress exert negative effects on ahNG. ${ }^{16-18}$ Intriguingly, reduction of hippocampal neurogenesis has been proposed to potentially contribute to cognitive decline and mood alterations associated with aging and neuropsychiatric disorders. ${ }^{11-13}$

ahNG is also highly susceptible to pharmacological modulation. Antidepressant drugs increase hippocampal neurogenesis in rodents, ${ }^{19-22}$ and an increased number of hippocampal NPC and granule neurons are reported in postmortem brain of MDD patients undergoing antidepressant therapy. ${ }^{23-25}$ In addition, several experimental studies demonstrate that antidepressants can counteract the inhibitory effect of stress on ahNG in rodent models of depressive-like disorder. ${ }^{12,26}$ Although still debated, it has been proposed that ahNG may be required for some behavioral effects of antidepressants in preclinical models and may potentially contribute to the antidepressant activity of these drugs also in the clinical setting. ${ }^{27,28}$ Emerging evidence also suggest that other psychoactive drugs, including the analgesic morphine and several drugs of abuse, result in molecular changes that may negatively affect different aspects of ahNG. ${ }^{29-31}$ Also these findings have important clinical implications since they raise the possibility that cognitive dysfunction and/or mood alteration in the setting of such drug use and/or abuse may, at least in part, be correlated with alterations in ahNG. ${ }^{13}$

\section{Deregulated hippocampal neurogenesis in chronic pain states}

As listed in Table 1, in rodent models, several preclinical studies have demonstrated a correlation between persistent pain and reduced hippocampal neurogenesis or blunted response of hippocampal NPC to proneurogenic stimuli..$^{32-37}$
Since chronic stress is a well-known negative regulator of ahNG, one may suggest that disrupted ahNG in chronic pain could be merely due to the stress associated with prolonged pain sufferance. On the other hand, it has been convincingly demonstrated that chronic immobilization stress exacerbates the deleterious effects of chronic pain on ahNG, in particular on proliferation and survival of newly generated cells. ${ }^{36}$ In a very elegant study, Mutso et al further investigated abnormalities in hippocampal functioning in a persistent pain state. ${ }^{34}$ Compared to sham-operated animals, neuropathic mice were proven unable to extinguish contextual fear and displayed increased anxiety-like behavior. Additionally, neuropathic mice displayed decreased hippocampal neurogenesis and altered short-term synaptic plasticity. ${ }^{34}$ Intriguingly, the same authors extended their observations to three distinct chronic pain patient subpopulations affected by osteoarthritis (OA), complex regional pain syndrome (CRPS), and chronic back pain (CBP). Compared with controls, CBP and CRPS, but not OA patients, had significantly reduced hippocampal volume bilaterally. Altogether, these findings prompted authors to suggest that hippocampus-mediated behavior, synaptic plasticity, and neurogenesis might be abnormal specifically in neuropathic pain, a clinical condition in which therapeutic approach is particularly challenging. The authors proposed that neuroplastic changes in animal models may be correlated with the reduction in hippocampal volume seen in chronic neuropathic pain patients. Moreover, they suggested that hippocampal abnormalities may potentially underlie learning and emotional deficits commonly observed in patients affected by neuropathic pain. ${ }^{34}$

At present, very limited information is available on the potential mechanisms whereby chronic pain may affect hippocampal neurogenesis and its behavioral consequences. It has been proposed that neuropathic pain induces a cluster of depressive-like symptoms and disrupts hippocampal plasticity via tumor necrosis factor receptor 1 (TNFR1) signaling. ${ }^{35}$ When neuropathic pain was induced in mice by sciatic nerve chronic constriction injury (CCI), behavioral effects were associated with impaired hippocampal neurogenesis and reduced expression of several neuroplasticity markers. Temporally, the onset of depressive-like behavior coincided with increased hippocampal TNF levels and decreased expression of TNF R2. Notably, TNFR1 ${ }^{-/}$mice neither developed depressive-like symptoms after CCI nor developed changes in hippocampal neurogenesis and plasticity, strongly suggesting a role of TNFR1-mediated TNF signaling as a possible regulator of these molecular, cellular, and behavioral events. ${ }^{35}$ 
Table I List of preclinical studies showing reduced or deregulated ahNG in chronic pain states

\begin{tabular}{|c|c|c|c|c|}
\hline Species & Chronic pain model & Effects on ahNG & Additional observations & Reference \\
\hline Rat & $\begin{array}{l}\text { Inflammatory pain } \\
\text { (CFA) }\end{array}$ & Reduced $\mathrm{BrdU}^{+}$cells & $\begin{array}{l}\text { Similar to chronic immobilization stress } \\
\text { effects }\end{array}$ & Duric and McCarson ${ }^{32}$ \\
\hline Mice (C57BI/6) & $\begin{array}{l}\text { Neuropathic pain } \\
\text { (SNL) }\end{array}$ & $\begin{array}{l}\text { Suppressed proneurogenic } \\
\text { effects of } E E \text { (reduced } \mathrm{DCX}^{+} \text {and } \\
\text { Neuro } \mathrm{D}^{+} \text {neuroblasts) }\end{array}$ & No effect on basal ahNG & Terada et $\mathrm{a}^{33}$ \\
\hline $\begin{array}{l}\text { Mice }(\text { C57BI/6; } \\
\text { DCX-EGFP } \\
\text { mice) }\end{array}$ & $\begin{array}{l}\text { Neuropathic pain } \\
\text { (SNI) }\end{array}$ & $\begin{array}{l}\text { Reduction of } \mathrm{DCX}^{+} / \mathrm{BrdU}^{+} \\
\text {neuroblasts }\end{array}$ & $\begin{array}{l}\text { Compared to sham animals, in SNI } \\
\text { mice: } \\
\text { Altered short-term hippocampal } \\
\text { synaptic plasticity } \\
\text { Inability to extinguish contextual fear } \\
\text { and increased anxiety-like behavior }\end{array}$ & Mutso et $\mathrm{al}^{34}$ \\
\hline $\begin{array}{l}\text { Mice } \\
(\mathrm{C} 57 \mathrm{BI} / 6) \\
\text { WT and } \\
\text { TNFRI } \\
-1-\text { mice }\end{array}$ & $\begin{array}{l}\text { Neuropathic pain } \\
(\mathrm{CCl})\end{array}$ & $\begin{array}{l}\text { Reduced } \mathrm{BrdU}^{+} / \mathrm{NeuN}^{+} \text {newly } \\
\text { generated neurons in WT mice } \\
\text { but not in } \mathrm{TNFRI}^{---} \text {mice }\end{array}$ & $\begin{array}{l}\mathrm{TNFRI}^{-1-} \text { mice did not develop changes } \\
\text { in hippocampal plasticity, and in } \\
\text { parallel, depressive-like symptoms } \\
\text { No reduced neurogenesis in olfactory } \\
\text { bulb }\end{array}$ & Dellarole et $\mathrm{a}^{35}$ \\
\hline Rat & $\begin{array}{l}\text { Neuropathic pain } \\
(\mathrm{CCl}) \\
\pm \text { chronic } \\
\text { immobilization stress }\end{array}$ & $\begin{array}{l}\text { Reduced proliferation, survival, } \\
\text { and neuronal differentiation of } \\
\text { newborn hippocampal cells }\end{array}$ & $\begin{array}{l}\text { Immobilization stress exacerbates the } \\
\text { negative effect of neuropathic pain on } \\
\text { ahNG }\end{array}$ & Romero-Grimaldi et $\mathrm{a}^{36}$ \\
\hline $\begin{array}{l}\text { Mice } \\
(\mathrm{C} 57 \mathrm{BI} / 6)\end{array}$ & $\begin{array}{l}\text { Inflammatory pain } \\
\text { (CFA) }\end{array}$ & $\begin{array}{l}\text { Reduced } \mathrm{DCX}^{+} / \mathrm{BrdU}^{+} \text {neuroblasts } \\
\text { Reduced morphological complexity } \\
\text { of newborn cells } \\
\text { Effects on ahNG alleviated by } \\
\text { EE-VEx }\end{array}$ & $\begin{array}{l}\text { Increasing ventral ahNG alleviates } \\
\text { perceptual and affective components of } \\
\text { chronic pain } \\
\text { Increasing dorsal ahNG alleviates } \\
\text { cognitive impairment in chronic pain } \\
\text { Overexpression of BDNF in the DG } \\
\text { mimicked the effects of EE-VEx }\end{array}$ & Zheng et $\mathrm{al}^{37}$ \\
\hline
\end{tabular}

Abbreviations: ahNG, adult hippocampal neurogenesis; BDNF, brain-derived neurotrophic factor; BrdU, Bromodeoxyuridine; CCl, chronic constriction injury; CFA, complete Freund adjuvant; DCX, doublecortin; DG, dentate gyrus; EE, environmental enrichment; EE-VEx, environmental enrichment + voluntary exercise; NeuN, neuronal nuclear antigen; NeuroD, neurogenic differentiation I; SNI, spared nerve injury; SNL, spinal nerve ligation; TNFR, tumor necrosis factor receptor; WT, wild-type.

The distinct roles of ahNG in cognition and emotion have raised the interesting possibility that adult-born DG granule neurons may be functionally heterogeneous. The hippocampus is indeed anatomically and functionally dissociated along the dorsoventral (or septotemporal) axis. The dorsal (septal pole) hippocampus is more involved in spatial learning, navigation, and memory, while the ventral (temporal pole) hippocampus may mediate anxiety/depression-related behaviors. Similarly, adult-born neurons in the dorsal hippocampus appear to be required for acquisition of contextual discrimination, whereas those in the ventral hippocampus are required for emotional behavior. ${ }^{38,39}$ Cognitive behavioral therapy, such as EE and voluntary exercise (EE-VEx), is under investigation as a nonpharmacological approach for chronic pain. By using a mouse model of inflammatory pain, Zheng et al demonstrated a distinct contribution of ahNG along the dorsoventral axis to EE-VEx's beneficial effects on different dimensions of chronic pain. ${ }^{37}$ Adult neurogenesis in the ventral hippocampus appeared to contribute to EE-VEx-mediated beneficial effects on perceptual and affective components of chronic pain. Conversely, neurogenesis in the dorsal hippocampal pole was involved in EE-VEx cognitive-enhancing effects in chronic pain. ${ }^{37}$

As it always occurs in emerging and controversial research fields, recently Apkarian et al published an interesting paper which raised additional questions about the meaning of ahNG alterations in chronic pain states. ${ }^{40}$ The authors manipulated hippocampal neurogenesis by several different approaches (pharmacologically, by X-irradiation, and by the use of genetically modified mice displaying increased or decreased ahNG) and tested its influence on both inflammatory and neuropathic pain-like behaviors. Surprisingly, they reported that downregulation of ahNG reversibly diminished persistent pain, while upregulation resulted in prolonged persistent pain. ${ }^{40}$ Based on these findings, they actually proposed that ahNG-mediated learning mechanisms may be involved in the development of persistent pain. ${ }^{40}$ This is the first proposal of a potentially active role of neurogenesis in pain modulation. In light of these results, future studies should more carefully dissect the contribution of ahNG to development, maintenance, and resolution of chronic pain states. 


\section{Potential clinical implications for deregulated ahNG in chronic pain states}

Chronic pain is a highly debilitating disease state. Clinical observations demonstrate that many patients affected by chronic pain exhibit increased anxiety and depression, suggesting the importance of affective or emotional pain components. ${ }^{41-43}$ Consistent with the concept of pain matrix, functional imaging studies also suggest that shared neural mechanisms may contribute to the comorbidity between chronic pain and anxiety/depression. In addition, there is clinical evidence that chronic pain may impair various aspects of cognition, including cognitive flexibility and memory capacities. ${ }^{44,45}$ Our current understanding of the molecular and cellular events that may underlie the comorbidity of chronic pain, depression, and cognitive impairment is still very limited. If and how persistent pain may affect potential brain areas, like the hippocampus, implicated in both cognition and emotional aspects has been largely unexplored. The occurrence of extensive preclinical evidence suggesting that chronic pain may induce profound changes in hippocampal plasticity, including deregulated hippocampal neurogenesis, should be further studied and addressed mechanistically. Based on a vast array of research observations, it is possible that dysregulated ahNG in chronic pain states may contribute, at least in part, to cognitive deficits and mood alterations in patients.

An additional aspect that should be taken into consideration for its clinical implications is the different impact of distinct therapeutic interventions in chronic pain. Preclinical data mark the importance of taking into account inhibition of ahNG as a potential long-term consequence of some opiates. Indeed since the initial report, ${ }^{29}$ extensive experimental data have been accumulated on the negative impact of chronic morphine administration on ahNG mainly via $\mu$-opioid receptors (MORs). ${ }^{31,46-51}$ The deleterious effect of morphine on hippocampal neurogenesis may potentially represent, among others, one mechanism by which morphine and other opiates exert long-lasting effects on the neural circuitries involved with cognition and mood regulation. Incidentally, cognitive dysfunction has been often reported in opiate drug abusers. ${ }^{48,52}$ Moreover, recent work has suggested an association between prolonged opiate use and the risk of new onset depression. ${ }^{53,54}$ Interestingly though, some atypical opiates do not negatively influence adult NSC and their progeny, at least in preclinical models. An in vivo study in the rat reported that chronically administered methadone does not reduce ahNG. ${ }^{55}$ Methadone is a strong opioid analgesic which, at clinically achievable concentrations, can also inhibit functional $N$-methyl-D-aspartate (NMDA) receptors, ${ }^{56}$ and NMDA antagonists can produce positive effects on hippocampal neurogenesis in rodents. ${ }^{57,58}$ Whether this pharmacological property of methadone may explain its lack of negative effects on ahNG likely deserves further investigation. In a similar manner, tapentadol, the first representative of a novel analgesic drug class referred to as MOR-NRI (MOR agonist and noradrenaline reuptake inhibitor), did not reduce hippocampal neurogenesis when chronically administered in adult mice at a clinically relevant dose.$^{59}$ It has been suggested that the noradrenergic component in tapentadol has the potential to counteract the adverse MOR-mediated effects on ahNG both in vivo and in vitro. ${ }^{59}$

Altogether, based on preclinical data, different risks of negative impact on ahNG are associated with distinct opiates which are commonly used in patients affected by chronic pain. ${ }^{31}$ At least in principle, the long-term use of analgesic drugs that do not cause dysfunction of ahNG may, in turn, result in less disruption of neurogenesis-associated functions in chronic pain patients. It should also be underlined that analgesic drugs which rather increase ahNG in preclinical models could be taken into consideration, at least in neuropathic pain where they are very effective. Indeed, the $\alpha 2 \delta$ ligands pregabalin/gabapentin ${ }^{61}$ and acetyl-L-carnitine ${ }^{62}$ have been demonstrated to significantly promote hippocampal neurogenesis in rodents. Interestingly, both drugs act via modulation of NF- $\mathrm{KB}$-mediated signaling, a pathway that has been shown to play a crucial role in the regulation of ahNG in response to several signals and drugs. ${ }^{61-67}$ Interestingly, both $\alpha 2 \delta$ ligands and acetyl-L-carnitine also exert antidepressant activity in rodent where depressive-like behavior was induced by chronic restraint or unpredictable chronic mild stress. ${ }^{61,62,68}$ Interestingly, the same drugs also produce antidepressant effects in patients. ${ }^{69,70}$ Again, at least in principle, analgesic drugs that promote ahNG could represent first option therapy since they may have beneficial effects also on emotional and, potentially, on cognitive aspects in chronic pain states. At present, no clinical data are available to support this hypothesis since this approach would require to monitor neurogenesis in vivo, and no such imaging techniques are currently applicable in human studies. On the other hand, in vivo imaging of neurogenesis has been achieved in mice using transgenic model systems supporting the idea that in a near future detection of neurogenesis could theoretically be achieved in humans using current imaging devices. ${ }^{71}$

Altogether, based on several preclinical observations, in the future, more studies should be devoted to a better 
understanding of how analgesic drugs differentially affect molecular and cellular aspects of ahNG and hippocampal function. Currently, several compounds acting at different targets are under development for effective chronic pain treatment. ${ }^{72-74}$ Potentially, future drug design may take into consideration the development of powerful analgesics that, by preserving or even promoting ahNG, may reduce the risk or prevent cognition and mood alterations in chronic pain patients.

\section{Disclosure}

In the past $\mathrm{MG}$ received research grants from drug companies manufacturing analgesic drugs, including Angelini SpA, Grunenthal GmbH, Pfizer, and Sigma Tau. The author reports no other conflicts of interest in this work.

\section{References}

1. Kempermann G, Gast D, Kronenberg G, Yamaguchi M, Gage FH. Early determination and long-term persistence of adult-generated new neurons in the hippocampus of mice. Development. 2003;130:391-399.

2. Seri B, Garcia-Verdugo JM, Collado-Morente L, McEwen BS, AlvarezBuylla A. Cell types, lineage, and architecture of the germinal zone in the adult dentate gyrus. J Comp Neurol. 2004;478:359-378.

3. Bond AM, Ming GL, Song H. Adult mammalian neural stem cell and neurogenesis: five decades later. Cell Stem Cell. 2015;17(4):385-395

4. Bergmann O, Spalding KL, Frisén J. Adult neurogenesis in humans. Cold Spring Harb Perspect Biol. 2015;7:a018994.

5. Shors TJ, Miesagaes G, Beylin A, Zhao M, Rydel T, Gould E. Neurogenesis in the adult is involved in the formation of trace memories. Nature. 2001;410(6826):372-376.

6. Aimone JB, Wiles J, Gage FH. Potential role for adult neurogenesis in the encoding of time in new memories. Nat Neurosci. 2006;9:723-727.

7. Denis-Donini S, Dellarole A, Crociara P, et al. Impaired adult neurogenesis associated with short-term memory defects in NF-kappaB p50-deficient mice. J Neurosci. 2008;28:3911-3919.

8. Deng W, Aimone JB, Gage FH. New neurons and new memories: how does adult hippocampal neurogenesis affect learning and memory? Nat Rev Neurosci. 2010;11:339-350.

9. Sahay A, Wilson DA, Hen R. Pattern separation: a common function for new neurons in hippocampus and olfactory bulb. Neuron. 2011;70:582-588.

10. Aimone JB, LiY, Lee SW, Clemenson GD, Deng W, Gage H. Regulation and function of adult neurogenesis: from genes to cognition. Physiol Rev. 2014;94:991-1026.

11. Kempermann G, Krebs J, Fabel K. The contribution of failing adult hippocampal neurogenesis to psychiatric disorders. Curr Opin Psychiatry. 2008;21(3):290-295.

12. Eisch AJ, Petrik D. Depression and hippocampal neurogenesis: a road to remission? Science. 2012;338:72-75.

13. Yun S, Reynolds RP, Masiulis I, Eisch AJ. Re-evaluating the link between neuropsychiatric disorders and dysregulated adult neurogenesis. Nat Med. 2016;22(11):1239-1247.

14. van Praag H, Shubert T, Zhao C, Gage F. Exercise enhances learning and hippocampal neurogenesis in aged mice. $J$ Neurosci. 2005;25(38):8680-8685.

15. Garthe A, Roeder I, Kempermann G. Mice in an enriched environment learn more flexibly because of adult hippocampal neurogenesis. Hippocampus. 2016;26(2):261-271.

16. Mirescu C, Gould E. Stress and adult neurogenesis. Hippocampus. 2006;16:233-238.

17. Schoenfeld TJ, Gould E. Stress, stress hormones, and adult neurogenesis. Exp Neurol. 2012;233:12-21.
18. Seib DR, Martin-Villalba A. Neurogenesis in the normal aging hippocampus: a mini-review. Gerontology. 2015;61(4):327-335.

19. Duman RS, Nakagawa S, Malberg J. Regulation of adult neurogenesis by antidepressant treatment. Neuropsychopharmacology. 2001;25(6): 836-844.

20. Malberg JE. Implications of adult hippocampal neurogenesis in antidepressant action. J Psych Neurosci. 2004;29(3):196-205.

21. Dranovsky A, Hen R. Hippocampal neurogenesis: regulation by stress and antidepressants. Biol Psych. 2006;59:1136-1143.

22. Bortolotto V, Cuccurazzu B, Canonico PL, Grilli M. NF- $\kappa B$ mediated regulation of adult hippocampal neurogenesis: relevance to mood disorders and antidepressant activity. Biomed Res Int. 2014;2014:612798.

23. Boldrini M, Underwood MD, Hen R, et al. Antidepressants increase neural progenitor cells in the human hippocampus. Neuropsychopharmacology. 2009;34(11):2376-2389.

24. Boldrini M, Hen R, Underwood MD, et al. Hippocampal angiogenesis and progenitor cell proliferation are increased with antidepressant use in major depression. Biol Psych. 2012;72(7):562-571.

25. Boldrini M, Santiago AN, Hen R, et al. Hippocampal granule neuron number and dentate gyrus volume in antidepressant-treated and untreated major depression. Neuropsychopharmacology. 2013;38(6):1068-1077.

26. Pittenger C, Duman RS. Stress, depression, and neuroplasticity: a convergence of mechanisms. Neuropsychopharmacology. 2008;33:88-109.

27. Santarelli L, Saxe M, Gross C, et al. Requirement of hippocampal neurogenesis for the behavioral effects of antidepressants. Science. 2003;301(5634):805-809.

28. David DJ, Samuels BA, Rainer Q, et al. Neurogenesis-dependent and -independent effects of fluoxetine in an animal model of anxiety/depression. Neuron. 2009;62(4):479-493.

29. Eisch AJ, Barrot M, Schad CA, Self DW, Nestler EJ. Opiates inhibit neurogenesis in the adult rat hippocampus. Proc Natl Acad Sci U SA. 2000;97(13):7579-7584.

30. Zhang Y, Loh HH, Law PY. Effect of opioid on adult hippocampal neurogenesis. Scientific World Journal. 2016;2016:2601264.

31. Bortolotto V, Grilli M. Opiate analgesics as negative modulators of adult hippocampal neurogenesis: potential implications in clinical practice. Front Pharmacol. 2017;8:254.

32. Duric V, McCarson KE. Persistent pain produces stress-like alteration in hippocampal neurogenesis and gene expression. J Pain. 2006;7(8):544-555.

33. Terada M, Kuzumaki N, Hareyama N, et al. Suppression of enriched environment-induced neurogenesis in a rodent model of neuropathic pain. Neurosci Lett. 2008;440(3):314-318.

34. Mutso AA, Radzicki D, Baliki MN, et al. Abnormalities in hippocampal functioning with persistent pain. J Neurosci. 2012;32(17):5747-5756.

35. Dellarole A, Morton P, Brambilla R, et al. Neuropathic pain- induced depressive like behavior and hippocampal neurogenesis and plasticity are dependent on TNFR1 signaling. Brain Behav Immun. 2014;41: $65-81$.

36. Romero-Grimaldi C, Berrocoso E, Alba-Delgado C, et al. Stress increases the negative effects of chronic pain on hippocampal neurogenesis. Anesth Analg. 2015;121(4):1078-1088.

37. Zheng J, Jiang YY, Xu LC, et al. Adult hippocampal neurogenesis along the dorsoventral axis contributes differentially to environmental enrichment combined with voluntary exercise in alleviating chronic inflammatory pain in mice. J Neurosci. 2017;37(15):4145-4157.

38. Tanti A, Belzung C. Neurogenesis along the septo-temporal axis of the hippocampus: are depression and the action of antidepressants regionspecific? Neuroscience. 2013;252:234-252.

39. O'Leary OF, Cryan JF. A ventral view on antidepressant action: roles for adult hippocampal neurogenesis along the dorsoventral axis. Trends Pharmacol Sci. 2014;35(12):675-687.

40. Apkarian AV, Mutso AA, Centeno MV, et al. Role of adult hippocampal neurogenesis in persistent pain. Pain. 2016;157(2):418-428.

41. MacWilliams LA, Cox BJ, Enns MW. Mood and anxiety disorders associated with chronic pain: an examination in a nationally representative sample. Pain. 2003;106(1-2):127-133. 
42. Baliki MN, Chialvo DR, Geha PY, et al. Chronic pain and the emotional brain: specific brain activity associated with spontaneous fluctuations of intensity of chronic back pain. J Neurosci. 2006;26(47):12165-12173.

43. Baliki MN, Apkarian AV. Nociception, pain, negative moods and behavior selection. Neuron. 2015;87(3):474-491.

44. Baker KS, Gibson S, Georgiou-Karistianis N, Roth RM, Giummarra MJ. Everyday executive functioning in chronic pain: specific deficits in working memory and emotional control, predicted by mood, medications and pain interference. Clin J Pain. 2016;32(8):673-680.

45. Moriarty O, Ruane N, O'Gorman D, et al. Cognitive impairment in patients with chronic neuropathic or radicular pain: an interaction of pain and age. Front Behav Neurosci. 2017;13(11):100.

46. Kahn L, Alonso G, Normand E, Manzoni OJ. Repeated morphine treatment alters polysialylated neural cell adhesion molecule, glutamate decarboxylase-67 expression and cell proliferation in the adult rat hippocampus. Eur J Neurosci. 2005;21(2):493-500.

47. Mandyam CD, Norris RD, Eisch AJ. Chronic morphine induces premature mitosis of proliferating cells in the adult mouse subgranular zone. J Neurosci Res. 2004;76(6):783-794.

48. Eisch AJ, Harburg GC. Opiates, psychostimulants, and adult hippocampal neurogenesis: insights for addiction and stem cell biology. Hippocampus. 2006;16(3):271-286.

49. Arguello AA, Harburg GC, Schonborn JR, Mandyam CD, Yamaguchi M, Eisch AJ. Time course of morphine's effects on adult hippocampal subgranular zone reveals preferential inhibition of cells in S phase of the cell cycle and a subpopulation of immature neurons. Neuroscience. 2008;157(1):70-79.

50. Fisher SJ, Arguello AA, Charlton JJ, Fuller DC, Zachariou V, Eisch AJ. Morphine blood levels, dependence, and regulation of hippocampal subgranular zone proliferation rely on administration paradigm. Neuroscience. 2008;151(4):1217-1224.

51. Zhang Y, Xu C, Zheng H, Loh HH, Law PY. Morphine modulates adult neurogenesis and contextual memory by impeding the maturation of neural progenitors. PLoS One. 2016;11(4):e0153628.

52. Canales JJ. Adult neurogenesis and the memories of drug addiction. Eur Arch Psychiatry Clin Neurosci. 2007;257(5):261-270.

53. Scherrer JF, Salas J, Lustman PJ, Burge S, Schneider FD; Residency Research Network of Texas (RRNeT) Investigators. Change in opioid dose and change in depression in a longitudinal primary care patient cohort. Pain. 2015;156(2):348-355.

54. Scherrer JF, Salas J, Copeland LA, et al. Increased risk of depression recurrence after initiation of prescription opioids in noncancer pain patients. J Pain. 2016;17(8):473-482.

55. Sankararaman A, Masiulis I, Richardson DR, Andersen JM, Mørland J, Eisch AJ. Methadone does not alter key parameters of adult hippocampal neurogenesis in the heroin-naïve rat. Neurosci Lett. 2012;516(1):99-104.

56. Callahan RJ, Au JD, Paul M, Liu C, Yost CS. Functional inhibition by methadone of N-methyl-D-aspartate receptors expressed in Xenopus oocytes: stereospecific and subunit effect. Anesth Analg. 2004;98(3):653-659.

57. Nacher J, Rosell DR, Alonso-Llosa G, McEwen BS. NMDA receptor antagonist treatment induces a long-lasting increase in the number of proliferating cells, PSA-NCAM-immunoreactive granule neurons and radial glia in the adult rat dentate gyrus. Eur $J$ Neurosci. 2001;13(3):512-520.

Journal of Pain Research

\section{Publish your work in this journal}

The Journal of Pain Research is an international, peer reviewed, open access, online journal that welcomes laboratory and clinical findings in the fields of pain research and the prevention and management of pain. Original research, reviews, symposium reports, hypothesis formation and commentaries are all considered for publication.
58. Maekawa M, Namba T, Suzuki E, Yuasa S, Kohsaka S, Uchino S. NMDA receptor antagonist memantine promotes cell proliferation and production of mature granule neurons in the adult hippocampus. Neurosci Res. 2009;63(4):259-266.

59. Tzschentke TM, Christoph T, Kögel B, et al. (-)-(1R,2R)-3-(3-dimethylamino-1-ethyl-2-methyl-propyl)-phenol hydrochloride (tapentadol $\mathrm{HCl}$ ): a novel mu-opioid receptor agonist/norepinephrine reuptake inhibitor with broad-spectrum analgesic properties. J Pharmacol Exp Ther. 2007;323(1):265-276.

60. Meneghini V, Cuccurazzu B, Bortolotto V, et al. The noradrenergic component in tapentadol action counteracts $\mu$-opioid receptor-mediated adverse effects on adult neurogenesis. Mol Pharmacol. 2014;85(5):658-670.

61. Valente V, Bortolotto V, Cuccurazzu B, et al. $\alpha 2 \delta$ ligands act as positive modulators of adult hippocampal neurogenesis and prevent depressionlike behavior induced by chronic restraint stress. Mol Pharmacol. 2013;82(2):271-280.

62. Cuccurazzu B, Bortolotto V, Valente MM, et al. Upregulation of mGlu2 receptors via NF- $\kappa B$ p 65 acetylation is involved in the Proneurogenic and antidepressant effects of acetyl-L-carnitine. Neuropsychopharmacology. 2013;38(11):2220-2230.

63. Meneghini V, Bortolotto V, Francese MT, et al. High-mobility group box-1 protein and $\beta$-amyloid oligomers promote neuronal differentiation of adult hippocampal neural progenitors via receptor for advanced glycation end products/nuclear factor- $\mathrm{\kappa B}$ axis: relevance for Alzheimer's disease. J Neurosci. 2013;33(14):6047-6059.

64. Valente MM, Allen M, Bortolotto V, et al. The MMP-1/PAR-1 axis enhances proliferation and neuronal differentiation of adult hippocampal neural progenitor cells. Neural Plast. 2015;2015:646595.

65. Bortolotto V, Grilli M. Every cloud has a silver lining: proneurogenic effects of A $\beta$ oligomers and HMGB-1 via activation of the RAGENF- $\mathrm{KB}$ axis. CNS Neurol Disord Drug Targets. Epub 2016 Aug 3.

66. Cvijetic S, Bortolotto V, Manfredi M, et al. Cell autonomous and noncell-autonomous role of NF- $\mathrm{\kappa B}$ p50 in astrocyte-mediated fate specification of adult neural progenitor cells. Glia. 2017;65(1):169-181.

67. Bortolotto V, Mancini F, Mangano G, et al. Proneurogenic effects of trazodone in murine and human neural progenitor cells. ACS Chem Neurosci. Epub 2017 Jul 3.

68. Nasca C, Xenos D, Berone Y, et al. L-acetylcarnitine causes rapid antidepressant effects through the epigenetic induction of mGlu2 receptors. Proc Natl Acad Sci U SA. 2013;110(12):4804-4809.

69. Pae CU. Pregabalin augmentation to antidepressants in patients with major depressive disorder. Prog Neuropsychopharmacol Biol Psychiatry. 2009;33(3):577-578.

70. Bersani G, Meco G, Denaro A, et al. L-acetylcarnitine in dysthymic disorder in elderly patients: a double-blind, multicenter, controlled randomized study vs. fluoxetine. Eur Neuropsychopharmacol. 2013;23(10):1219-1225.

71. Ortega F, Costa MR. Live imaging of adult neural stem cells in rodents. Front Neurosci. 2016;10:78.

72. Sasikumar TK, Qiang L, Burnett D, et al. A-ring modifications on the triazafluorenone core structure and their mGluR1 antagonist properties. Bioorg Med Chem Lett. 2010;20:2474-2477.

73. Chang DS, Raghavan R, Christiansen S, Cohen SP. Emerging targets in treating pain. Curr Opin Anaesthesiol. 2015;28(4):379-397.

74. Yaksh TL, Woller SA, Ramachandra R, Sorkin LS. The search of novel analgesics: targets and mechanisms. F1000Prime Rep. 2015;7:56.

The manuscript management system is completely online and includes a very quick and fair peer-review system, which is all easy to use. Visit http://www.dovepress.com/testimonials.php to read real quotes from published authors. 